\title{
A novel MSMB-related microprotein in the postovulatory egg coats of marsupials
}

\author{
Stephen Frankenberg*, Jane Fenelon, Bonnie Dopheide, Geoff Shaw and Marilyn B Renfree
}

\begin{abstract}
Background: Early marsupial conceptuses differ markedly from those of eutherian mammals, especially during cleavage and early blastocyst stages of development. Additionally, in marsupials the zona pellucida is surrounded by two acellular layers, the mucoid coat and shell, which are formed from secretions from the reproductive tract.

Results: We report the identification of a novel postovulatory coat component in marsupials, which we call uterinesecreted microprotein (USM). USM belongs to a family of disulfide-rich microproteins of unconfirmed function that is found throughout deuterostomes and in some protostomes, and includes $\beta$-microseminoprotein (MSMB) and prostate-associated microseminoprotein (MSMP). We describe the evolution of this family in detail, including USM-related sequences in other vertebrates. The orthologue of USM in the tammar wallaby, USM1, is expressed by the endometrium with a dynamic temporal profile, possibly under the control of progesterone.

Conclusions: USM appears to have evolved in a mammalian ancestor specifically as a component of the postovulatory coats. By analogy with the known properties of MSMB, it may have roles in regulating sperm motility/survival or in the immune system. However, its C-terminal domain is greatly truncated compared with $M S M B$, suggesting a divergent function.
\end{abstract}

\section{Background}

Marsupial conceptuses are surrounded by three extracellular investments (reviewed [1]). The innermost layer, the zona pellucida, is deposited during oogenesis and occurs in all mammals. After ovulation and fertilisation, it becomes surrounded by a thick, translucent layer mucoid coat that is deposited during passage through the oviduct and traps non-fertilising sperm. By the time the conceptus arrives in the uterus, the mucoid coat has become surrounded by a thin, dense, shell coat derived mainly from secretions in the utero-tubal junction and the uterus [2-4]. During the period we define as "preliminary blastocyst expansion", the mucoid coat narrows as it becomes compressed between the expanding zona pellucida and the outer shell coat. During "secondary expansion", the shell coat itself expands from an initial diameter of about $200-300 \mu \mathrm{m}$ up to $\sim 17 \mathrm{~mm}$, increasing its volume dramatically from $0.001 \mathrm{~mm}^{3}$ to $>0.250$ $\mathrm{mm}^{3}$ [5]. The shell coat finally ruptures approximately two-thirds of the way through pregnancy, or 3-8 days

\footnotetext{
* Correspondence: srfr@unimelb.edu.au

ARC Centre of Excellence for Kangaroo Genomics and Department of Zoology, University of Melbourne, Parkville, Victoria, Australia
}

before birth [6], under the influence of proteases secreted by the endometrium [7], after which attachment occurs.

A previous study [2] made substantial progress in identifying components of the postovulatory coats of the brushtail possum (Trichosurus vulpecula) and the stripefaced dunnart (Sminthopsis macroura). The authors isolated individual protein components by electrophoresis and sequenced their $\mathrm{N}$-terminal regions. The short sequences obtained (12-15 residues) for twelve excised protein bands (seven from possum and five from dunnart) could not initially be identified due to insufficient bioinformatic resources for these species at the time. Since that study, one band was identified as similar to $\tau$ crystallin/enolase 1 and termed CP4 (coat protein 4) [8].

Genomes have now been sequenced from two marsupials - the South American grey short-tailed opossum (Monodelphis domestica) [9], and more recently the Australian tammar wallaby (Macropus eugenii) (in press). With these new resources at hand, we re-examined the published protein sequences of Casey et al. [2] and identified one of them from the brushtail possum. We show that the gene encoding this protein, which we

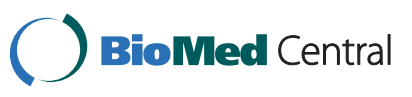

(c) 2011 Frankenberg et al; licensee BioMed Central Ltd. This is an Open Access article distributed under the terms of the Creative Commons Attribution License (http://creativecommons.org/licenses/by/2.0), which permits unrestricted use, distribution, and reproduction in any medium, provided the original work is properly cited. 
call uterinesecreted microprotein $(U S M)$ is a paralogue of MSMB ( $\beta$-microseminoprotein; also called PSP94, $\beta$ inhibin and IgBF). MSMB is a disulfide-rich, low molecular weight protein that is a major component of seminal fluid and is strongly expressed in the prostate gland as well as in other tissues, especially of the reproductive system and in mucosal membranes. Its specific function is not known, but it may have roles in inhibition of sperm motility $[10,11]$, suppression of immune response against allogeneic sperm [12], toxin defence [13,14], pituitary-gonadal axis signalling [15-17] and suppression of prostate tumorigenesis [18-22]. Very little is known of MSMP, which is similar to MSMB but more highly conserved among species, apart from its expression in a prostate cancer cell line [23]. USM is similar to both MSMB and MSMP in its conserved sequence of disulfide bond-forming cysteine residues, but most of the region homologous to the $\mathrm{C}$-terminal domain of MSMB is absent. In this study, we examine the evolution of USM/MSMB/MSMP-related microproteins in vertebrates. We discuss how, as a component of the marsupial postovulatory coats, USM could provide important clues for elucidating the roles of MSMB and other related proteins, with possible applications in prostate cancer, immunity and fertility control.

\section{Results \& Discussion}

\section{Identification of postovulatory coat proteins}

Protein sequences from Casey et al [2] were used to search GenBank databases using the tBLASTn algorithm with low-stringency search parameters. The alignments of sequences from Casey et al [2] with an expressed sequence tag [GenBank accession EG617409] derived from the reproductive tract of the brushtail possum is shown in Figure 1. The major sequence from Band 5 $(14 \mathrm{kDa})$ matched closely the translated possum EST, while minor sequences from Bands 3 (22 kDa), 4 (17 $\mathrm{kDa})$ and 5 also showed identity. We named this protein uterine secreted microprotein (USM).

The translated sequence of the possum EST was used to identify exons in the tammar wallaby (Macropus eugenii) whole genome shotgun (WGS) database, which revealed an apparent four-exon structure with an open reading frame spanning Exons 2-4 (Figure 2). A second, more divergent homologue was also identified bioinformatically. We refer to these genes respectively as tammar USM1 and USM2. Conserved exons in the opossum genome were identified as a homologue of USM.

Exon 1 of tammar USM1 was determined by 5' RACE and differed from that of the brushtail possum EST. In the opossum genome, Exons 2-4 of the brushtail possum EST map to Chromosome 1 whereas the "first exon" maps to Chromosome 8, immediately upstream of

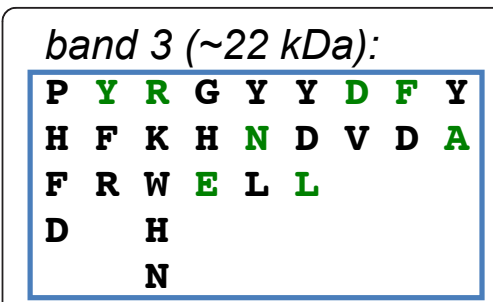

band 4 ( 17 ka):

$\begin{array}{|lllllllllllllll|}\mathbf{S} & \mathbf{D} & \mathbf{R} & \mathbf{Y} & \mathbf{A} & \mathbf{V} & \mathbf{D} & \mathbf{-} & \mathbf{P} & \mathbf{A} & \mathbf{D} & - & \mathbf{D} & \mathbf{P} & \mathbf{N} \\ \mathbf{A} & \mathbf{H} & \mathbf{Y} & \mathbf{W} & \mathbf{E} & \mathbf{N} & \mathbf{L} & \mathbf{T} & \mathbf{F} & \mathbf{Y} & \mathbf{T} & \mathbf{N} & \mathbf{P} & \mathbf{K} & \\ \mathbf{E} & \mathbf{I} & \mathbf{F} & \mathbf{L} & \mathbf{N} & \mathbf{T} & & \mathbf{F} & \mathbf{A} & & \mathbf{V} & \mathbf{R} & & & \end{array}$

band 5 ( 14 kDa):

\begin{tabular}{|lllllllllllllll}
\hline $\mathbf{A}$ & - & $\mathbf{Y}$ & $\mathbf{R}$ & $\mathbf{E}$ & $\mathbf{N}$ & $\mathbf{L}$ & $\mathbf{D}$ & $\mathbf{F}$ & $\mathbf{A}$ & $\mathbf{T}$ & $\mathbf{N}$ & $\mathbf{P}$ & $\mathbf{V}$ & $\mathbf{G}$ \\
$\mathbf{W}$ & $\mathbf{Y}$ & $\mathbf{R}$ & $\mathbf{E}$ & $\mathbf{N}$ & $\mathbf{L}$ & $\mathbf{D}$ & $\mathbf{F}$ & $\mathbf{A}$ & $\mathbf{T}$ & $\mathbf{N}$ & $\mathbf{P}$ & $\mathbf{V}$ & $\mathbf{G}$ & \\
$\mathbf{E}$ & $\mathbf{N}$ & $\mathbf{L}$ & & $\mathbf{F}$ & $\mathbf{A}$ & $\mathbf{T}$ & & $\mathbf{P}$ & & & & & & \\
\hline $\mathbf{A}$ & $\mathbf{C}$ & $\mathbf{Y}$ & $\mathbf{R}$ & $\mathbf{E}$ & $\mathbf{N}$ & $\mathbf{L}$ & $\mathbf{D}$ & $\mathbf{F}$ & $\mathbf{A}$ & $\mathbf{T}$ & $\mathbf{N}$ & $\mathbf{P}$ & $\mathbf{V}$ & $\mathbf{G}$ \\
possum & EST (accession & EG & (ac17409)
\end{tabular}

Figure 1 Identification of a brushtail possum coat protein component from published sequences. Published sequences (boxed) of electrophoresed protein bands from possum postovulatory coats [2] are aligned with a translation of brushtail possum expressed sequence tag (EST), GenBank accession EG617409, highlighted in blue. Aligned residues between the translated EST and the major sequence of band 5 are shown in red. Additional residues within the sub-sequences of bands 3-5 that also match the EST are shown in green. In bands 3 and 5, these are one residue out of phase. The approximate molecular weights indicated are those estimated by Casey et al. [2]

the third exon of another gene, WASH1. To resolve this discrepancy and to characterise fully the genomic locus of tammar USM1, we isolated and sequenced a tammar genomic BAC clone containing the gene. In a single assembled 89.8-kb contig of BAC sequence [GenBank accession JN251945], no sequence matching the "first exon" of the brushtail possum EST was present in the $17.1 \mathrm{~kb}$ upstream of Exon 2, however Exon 1 as identified by 5' RACE was located upstream of Exon 2, as expected. USM2 was located downstream of USM1 in the BAC sequence and in the same orientation. USM2 also contains exons homologous to Exons 1-4 (Figure 3 ). We conclude that the "first exon" of the brushtail possum EST represents an anomaly or an artefact of cDNA library construction. Downstream of USM2 and in the same orientation as USM1 and USM2 in the BAC sequence, we identified the first 8 exons of ELP3 (Figure $3)$, which also flanks USM in the opossum genome. This confirmed that opossum USM is orthologous to the tammar USM1/USM2 cluster. However, unlike in the tammar, no duplicate of USM was found at this locus in the opossum. 


\begin{tabular}{|c|c|}
\hline $\begin{array}{l}\text { opossum } \\
\text { brushtail possum } \\
\text { tammar }\end{array}$ & $\begin{array}{l}\text { TT TCCCAATCCATCGGTCAAAGCTCATT TCTTCTCTTGGGCACAGGCATCAGCTTCATTCTGT TCATCGGAT } \\
\text { TCATCTAATCCATCATTCAAGGCTCCTCTCTCTTCCCAGACACAGTTGTCACCATCAGCCTGTTCATCAGAT } \\
\text { EXON } 1\end{array}$ \\
\hline $\begin{array}{l}\text { opossum } \\
\text { brushtail possum } \\
\text { tammar }\end{array}$ & 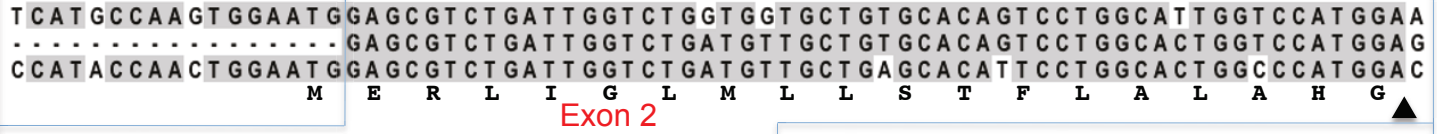 \\
\hline $\begin{array}{l}\text { opossum } \\
\text { brushtail possum } \\
\text { tammar }\end{array}$ & 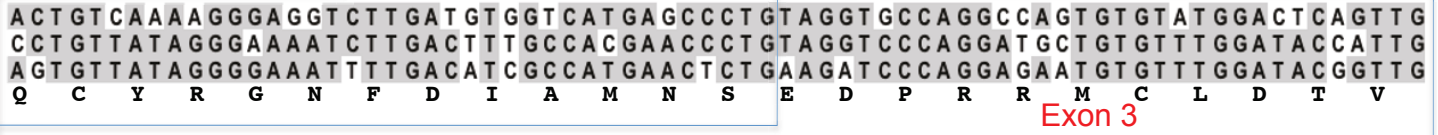 \\
\hline $\begin{array}{l}\text { opossum } \\
\text { brushtail possum } \\
\text { tammar }\end{array}$ & 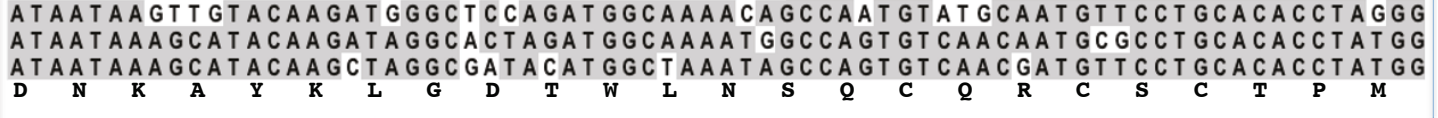 \\
\hline $\begin{array}{l}\text { opossum } \\
\text { brushtail possum } \\
\text { tammar }\end{array}$ & 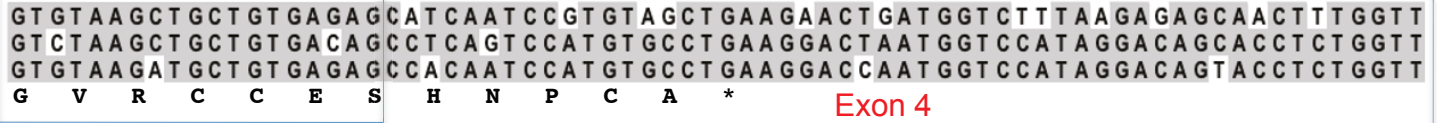 \\
\hline $\begin{array}{l}\text { opossum } \\
\text { brushtail possum } \\
\text { tammar }\end{array}$ & 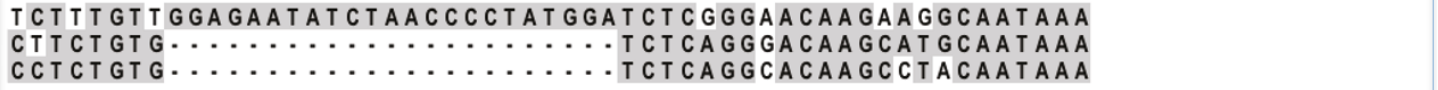 \\
\hline \multicolumn{2}{|c|}{$\begin{array}{l}\text { Figure } 2 \text { Sequence and translation of tammar USM1 and opossum USM aligned with brushtail possum EST. Note that the "first exon" in } \\
\text { the brushtail possum EST is excluded from this alignment, as it appears to be an artefact (see text). Sequences extend from the transcription } \\
\text { start site, determined for tammar USM1 by 5' RACE, to the predicted polyadenylation signal. The signal peptide cleavage site is indicated by an } \\
\text { arrowhead. }\end{array}$} \\
\hline
\end{tabular}

A signal peptide cleavage site was predicted at the same position in all three species (Figure 2 and additional file 1: Protein_alignment.pdf), strongly indicative of a secretory protein and consistent with a role in the extracellular postovulatory coats. In the brushtail possum, the predicted cleavage site also immediately precedes the major sequence from band 5 (compare Figure 1 and additional file 1: Protein_alignment.pdf), which was obtained by $\mathrm{N}$-terminal sequencing.

In eutherian sequence databases, the highest translated sequence identity with the USM genes was found in orthologues of $M S M B$ and another related gene, MSMP (also called PSMP). USM is not an orthologue of either of these genes, however, as other genes corresponding respectively to orthologues of $M S M B$ and MSMP were identified in both tammar and opossum genomes. Thus USM is a novel mammalian gene that is absent in the eutherian lineage.

The four-exon structure of marsupial USM genes is similar to that of $M S M B$, including a predicted

Figure 3 Structure of sequenced tammar BAC clone. The
positions of exons of USM1, USM2 and EPL3 within a single $89.8 \mathrm{kDa}$
contig sequenced from a tammar genomic BAC clone are shown,
drawn to scale. Arrows denote the orientation (5'-to-3') of the sense
strand of coding regions.

translation initiation codon in the three 3'-most nucleotides of Exon 1 (Figure 4). USM and MSMB both differ from $M S M P$, which is comprised of only three coding exons, homologous to $U S M / M S M B$ Exons 2-4. Thus for ease of comparison, the exons of MSMP are hereafter referred to according to their homology with USM/ $M S M B$ exons. The full coding region and splicing structure of tammar USM1 was confirmed by RT-PCR followed by cloning and sequencing (not shown).

\section{The USM/MSMB/MSMP gene family}

To examine the evolution of the MSMB/MSMP/USM gene family, we performed low stringency tBLASTn searches of GenBank databases and identified numerous homologues in vertebrate genomes as well as in those of lower deuterostomes, including Ciona spp. (Urochordata), Branchistoma lanceolatum (Cephalochordata) and Stronglyocentrotus purpuratus (Echinodermata), and of protostomes, including those recently reported in the phyla Mollusca and Rotifera [24]. (See additional file 2: Sequence_sources.pdf for sources of all sequences used in this study.) Most of the identified genes were previously unreported. Alignment of a large number of translated sequences (not shown) suggested a complex pattern of evolution with rapid sequence changes and gene duplication events. As previously reported [23], MSMP showed the strongest conservation among vertebrates. Because of the large number of amino acid substitutions, the phylogenetic relationship between family 


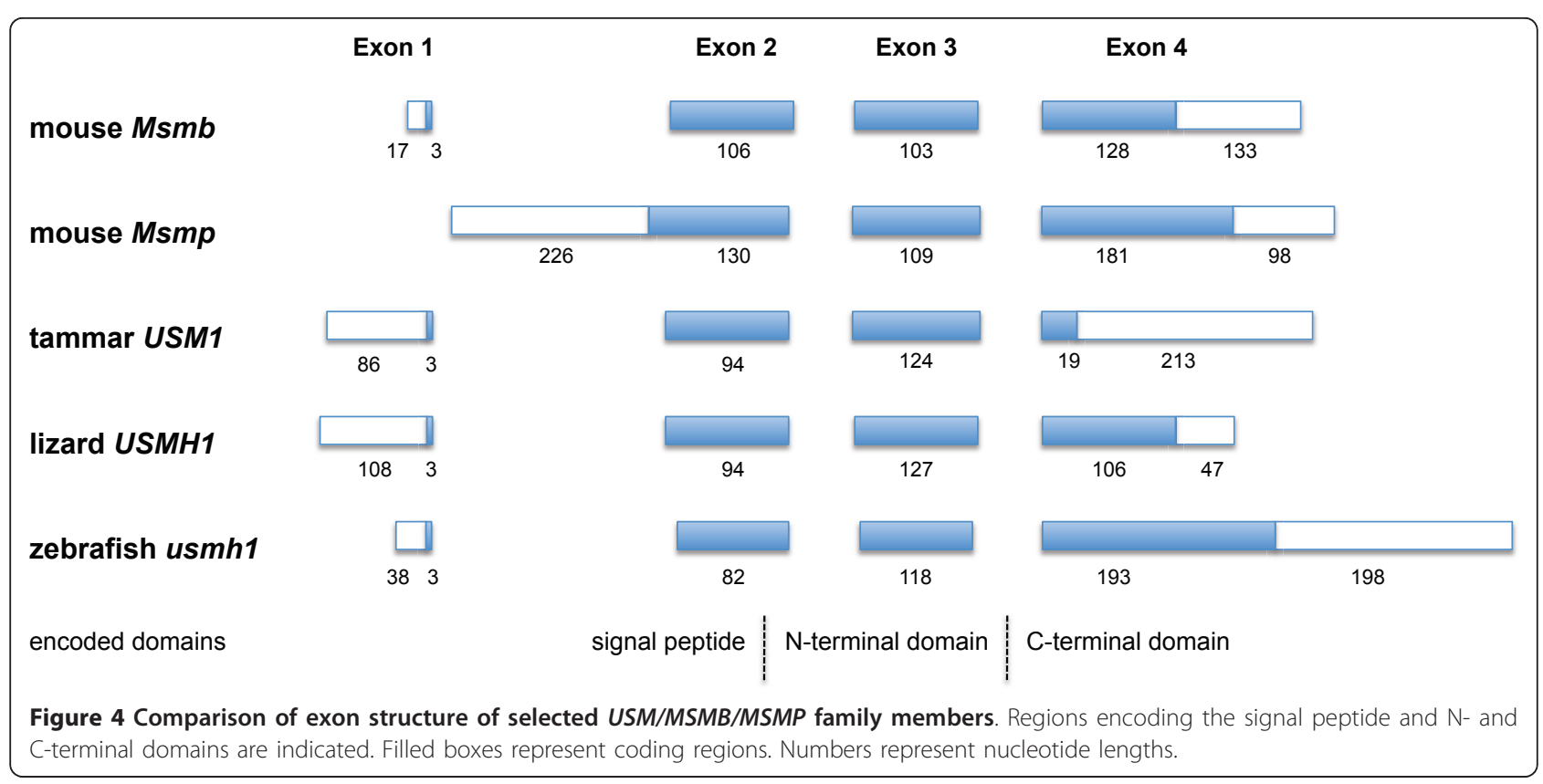

members from distantly related species was not readily resolved by standard bootstrapping methods, with the exception of MSMP-like genes (not shown). Nevertheless, three broad sub-families appeared to be represented among vertebrates: $M S M P$-like, MSMB-like and USMlike(see additional file 3: Tree.pdf).

\section{Conserved synteny among MSMB/MSMP/USM family members}

To clarify the relationships among MSMB/MSMP/USM family members, we examined their conservation of synteny with flanking genes. We focussed particularly on $M S M B$-like and USM-like genes as they showed the most sequence variability. The most informative syntenic groups are summarised in Figure 5.

In the opossum genome, USM flanks ARID5A while 14 tandem copies of $M S M B$ flank FAM21C and $A N U B L 1$. In the chicken, 3 tandem copies of $M S M B$ also flank $F A M 21 C$ and $A N U B L 1$, which are located near $A R I D 5 B$ (a paralogue of ARID5A) on chromosome 6, whereas no $M S M B / U S M$-like gene is located near $A R I D 5 A$ on chromosome 22. By contrast, USM-like genes lie close to $A R I D 5 A$ in the lizard genome and arid5 $a$ in the zebrafish genome. This suggests that the same duplication event that generated $A R I D 5 A$ and $A R I D 5 B$ also generated USM-like and MSMB-like genes, respectively. This duplication event can be traced to prior to the divergence of the teleost fish lineage (which has also undergone its own genome duplication event [25]) and is associated with the generation of other paralogous pairs (ANTRX1/ANTRXL and others not shown) that variably cluster with $A R I D 5 A / A R I D 5 B$ in vertebrate genomes (Figure 5). Both of these paralogous syntenic groups variably contain a homologue of PPYR1, with some lineages (such as lizard and zebrafish) containing a homologue in both syntenic groups.

\section{USM homologues in other vertebrates}

The presence of paralogous syntenic clusters conserved throughout vertebrates allowed orthologues of USM to be clearly identified. Among non-mammalian tetrapods, the most similar sequence to USM found was from the genome of the green anole lizard (Anolis carolinensis). Multiple copies of USM-related genes in the lizard flank $A R I D 5 A$, as does opossum USM and a cluster of three $U S M$-like genes in the zebrafish genome (Figure 5). These genes appear to be orthologous with respect to their origin, thus we refer to the lizard genes as USMH1 to -7 (USM homologue 1 to 7) and the zebrafish genes as usmh1 to -3 (USM homologue 1 to 3 ). They may not have equivalent function to USM, however, as the lizard and zebrafish genes have retained a complete Exon 4 encoding the C-terminal domain, in contrast to marsupial USM genes in which the open reading frame encoding this domain is greatly truncated. They also have four coding exons (Figure 4), which is supported by transcript evidence (see additional file 2: Sequence_sources. pdf). Published cDNA sequences from the Habu snake (Trimeresurus flavoviridis) [26] are similar to the lizard $U S M H$ genes. Like the lizard and zebrafish $U S M H$ genes, the snake genes are more similar to each other (not shown), suggesting that they also represent a lineage-specific expansion in copy number. These genes encode small serum proteins, SSP1-5, which appear to 


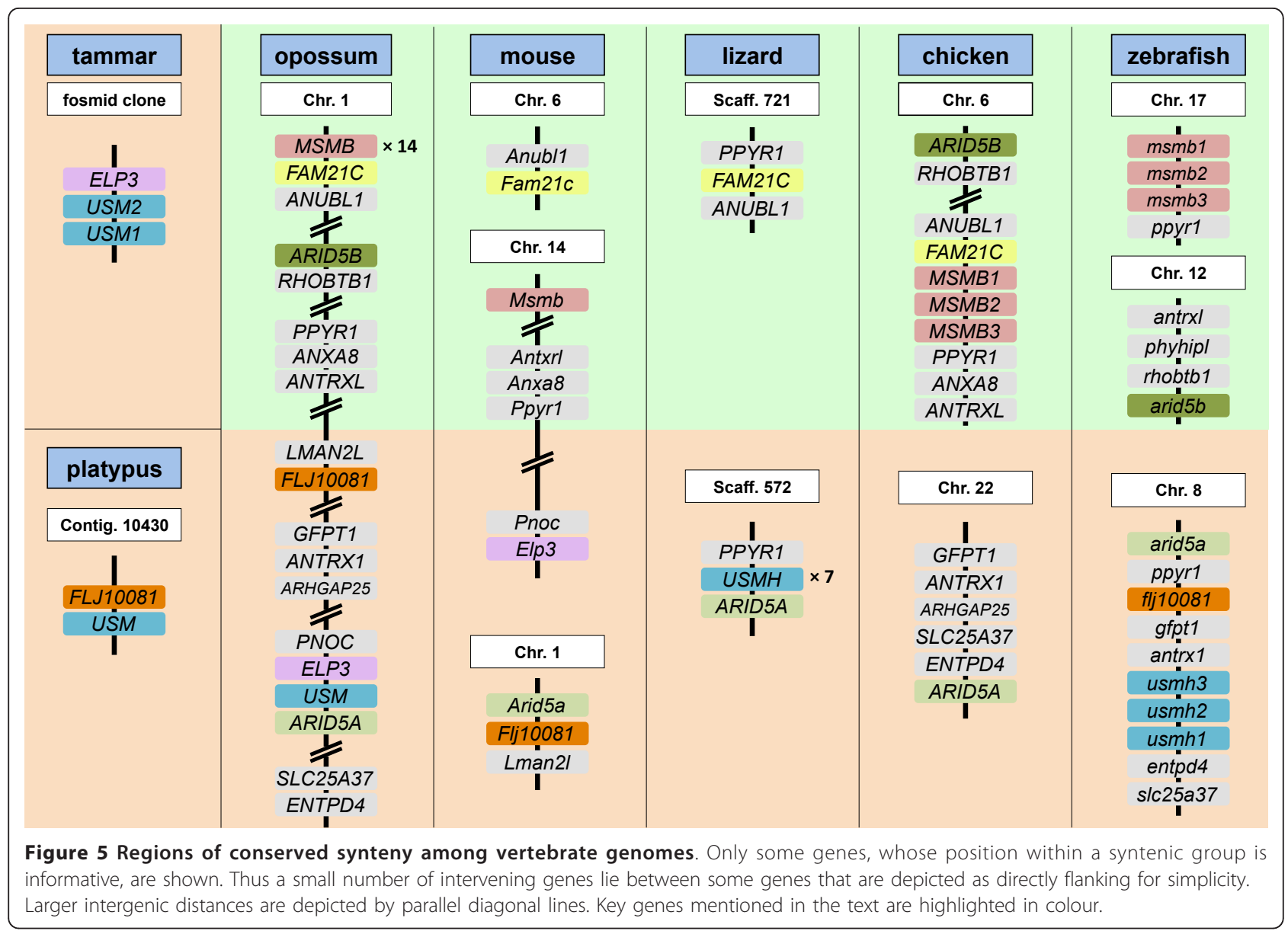

have a role in protection against the snake's own venom rather than in reproduction [13,14]. USMH-like sequences were also found in cDNAs derived from mixed tissues of the channel catfish (Ictalurus punctatus). According to the NCBI UniGene EST expression profiles, zebrafish usmh transcripts are found largely in the reproductive tract and consist mostly of usmh2 and usmh3 transcripts. Although it is possible that USMH proteins in other vertebrates also contribute to postovulatory coats, this appears unlikely due to their apparent additional expression in non-reproductive tract tissues. Furthermore, no specifically USM-like sequences were identified in the two sequenced avian genomes, chicken (Gallus gallus) and zebra finch (Taeniopygia guttata), in which conservation of postovulatory coat proteins might be expected. Thus it appears that a USMH gene evolved a novel role in the postovulatory coats of a common mammalian ancestor.

An apparent orthologue of USM is also present in the genome of the platypus (Ornithorhynchus anatinus), based on sequence similarity of Exons 1-3 and proximity to an orthologue of Flj1008, which also flanks Arid5a on mouse chromosome 1 (Figure 5). However platypus
Exon 4 could not be identified either manually or using gene prediction software, thus it could not be determined whether it encodes the same C-terminal truncation as marsupial USM. Our failure to detect Exon 4 argues that it probably has a truncated open reading frame and therefore platypus $U S M$ is likely to be functionally equivalent to marsupial $U S M$ rather than other vertebrate $U S M H$ genes.

\section{MSMB paralogues in birds and marsupials}

Our phylogenetic analysis of avian MSMB homologues revealed three distinct but previously unrecognised paralogous groups. The three chicken paralogues, which we term avian MSMB1, MSMB2 and MSMB3, flank each other on chromosome 6. Thus unlike in New World monkeys [27], in which multiple copies of $M S M B$ appear to have arisen independently, avian $M S M B$ paralogues are apparently conserved. Furthermore, each avian $M S M B$ paralogue shows high conservation in its translated sequence with its respective orthologues. Previously characterised sequences from chicken and ostrich (Struthio camelus) designated as MSMB [15,28] correspond to $M S M B 1$, while the gene currently 
annotated as $M S M B$ by the NCBI "Gene" database http://www.ncbi.nlm.nih.gov/gene?term $=\mathrm{msmb} \% 20$ gallus corresponds to MSMB2. A partial transcript of MSMB3 from chicken [GenBank accession DT655693] is annotated as being derived from reproductive tract ("testis, ovary and oviduct"), while a full transcript from duck (Anas platyrhynchos) [GenBank accession HO188240] was derived from a screen for genes expressed in the epithelium of the magnum (part of the reproductive tract) and correlated with high egg hatchability [29].

Avian MSMB1-3 genes differ markedly from each other in their degree of conservation. Translated sequence identities of the MSMB paralogues of zebra finch (order Passeriformes) were compared with their respective orthologues from Anseriformes (duck) and/or Galliformes (chicken, duck and turkey), the latter two orders forming a monophyletic clade [30]. Conservation is notably higher among MSMB3 orthologues (81-82\% amino acid identity) compared with MSMB1 (54-60\%) and MSMB2 (53-56\%) (see additional file 4: avian_MSMBs.pdf for table of sequence identities and similarities). The pattern was similar when comparing within Galliformes (chicken versus turkey): $83 \%$ amino acid identity for $M S M B 1,89 \%$ for $M S M B 2$ and $98 \%$ for $M S M B 3$. Mouse $M s m b$ is more similar to avian MSMB2 (32-36\% amino acid identity) than either MSMB1 (25$28 \%)$ or MSMB3 (23-25\%). These data suggest that avian $M S M B 3$ has acquired a novel, specialised role in birds distinct from that of other vertebrate $M S M B$ homologues. Considering the tissue source of the only two known transcripts, this role is likely to be related to reproduction. Ostrich MSMB1 was originally identified in the pituitary gland [15], supportive of a previously proposed role in the pituitary-gonadal axis $[17,19,20]$, although this role was later refuted [31,32].

In the opossum, we identified fourteen paralogues of $M S M B$, which we termed MSMB1 to -14, flanking each other on chromosome 1 (Figure 5). Similarly in the tammar, we identified at least ten presumed MSMB paralogues, although not all exons could be identified and their synteny could not be confirmed. One tammar homologue, designated $M S M B 1$, is very similar to opossum $M S M B 1$ and presumably orthologous to it. MSMB1 from tammar and opossum are strongly divergent from the other $M S M B$ homologues of both species and are significantly longer within Exon 3 (not shown). Thus only the $M S M B$ paralogues that flank MSMB1 (presumably in tammar as well as opossum), but not MSMB1 itself, have undergone multiple duplications independently within each lineage.

The above conclusions in birds and marsupials are supported by phylogenetic analysis (Figure 6). Significant (> 70\%) bootstrap values were obtained supporting orthology of avian MSMB1, -2 and -3 , respectively,

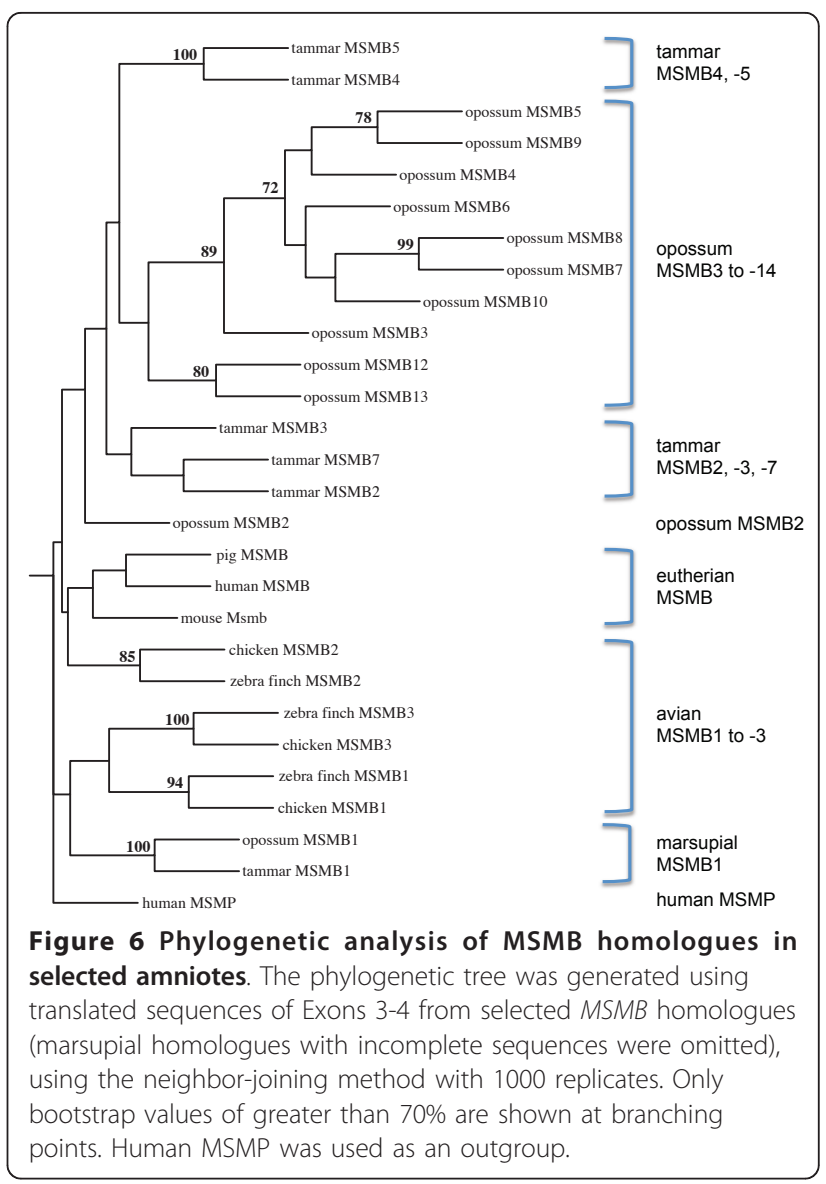

between chicken and zebra finch, and of marsupial MSMB1 between opossum and tammar. No marsupial homologues other than MSMB1 showed significant bootstrap values between tammar and opossum, whereas homologues from the same species tended to cluster together within the phylogenetic tree, indicative of lineage-specific duplication events.

\section{MSMB-like genes in protostomes}

Protostomal $M S M B$-like genes were identified mostly from the phylum Mollusca, including bivalves, gastropods and cephalopods, with one sequence from Rotifera. Additional identified transcript sequences were from a cDNA library derived from floral bulbs of Lewis' monkeyflower (Mimulus lewisii), a flowering plant. These are assumed to have arisen from contamination of the floral buds by a terrestrial gastropod (a slug or a snail) (H.D. Bradshaw, pers. comm.).

Phylogenetic analysis of all the protostomal MSMBlike translated sequences did not entirely reflect the species' taxonomic relationship (Figure 7), suggesting that not all the sequences are orthologous to each other. Most notably, the similarity between a sequence from a cephalopod, Euprymna scolopes, and the "Mimulus 


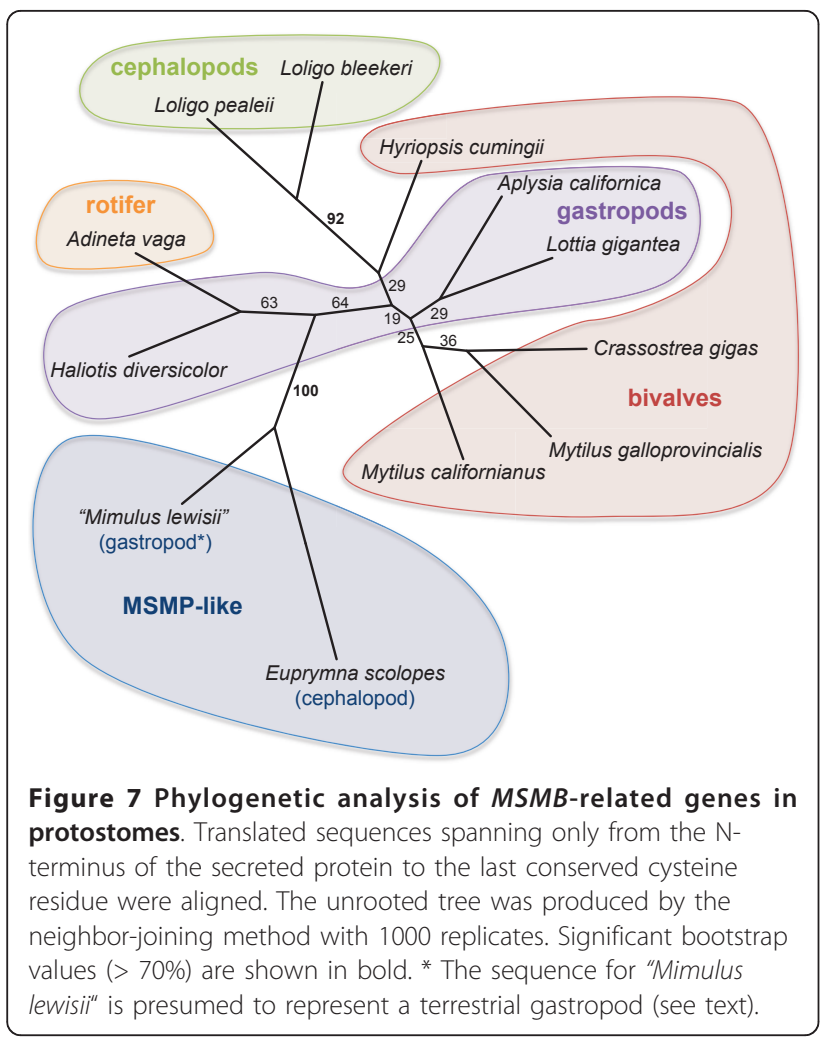

lewisii“" (presumed terrestrial gastropod) sequence is stronger (100\% bootstrap) than between any other sequence pairs, including between congeneric species (92\% for Loligo spp.; 25\% for Mytilus spp.). This suggests that the former sequences represent a gene that is subject to more evolutionary constraints, similarly to MSMP in vertebrates. Indeed, the sequences from Euprymna scolopes and "Mimulus lewisii" appear to share some features that are highly conserved in vertebrate MSMPs, such as a serine-alanine motif near the C-terminus (not shown). Thus it is possible that these two sequences represent distant orthologues of MSMP.

The California sea hare (Aplysia californica; Gastropoda) is the only mollusc currently with a WGS sequencing project. The sea hare $M S M B$-like sequence is located on the same genomic scaffold (Scaffold 217 of genome build Broad 2.0/aplCal1) as a member of the $K L H L$ (Kelch-like) gene family. KLHL genes also respectively occupy the syntenic groups that include $M S M B$ or USM/USMH in vertebrates (not shown). Together these data suggest a divergence between the MSMP and $U S M / M S M B$ lineages in a bilaterian common ancestor.

\section{Predicted tertiary structure of marsupial USM}

Almost all USM/MSMB/MSMP family members share a conserved pattern of ten disulfide-forming cysteine residues, whereas marsupial USM has only eight cysteine residues due to a truncated reading frame in Exon 4 (Figure 8a). The disulfide bond pairings of cysteine residues has been partially determined [15] and then later refined [33,34]. A recent crystallographic analysis of human MSMB [35] showed that the N-terminal domain consists of six $\beta$-strands ( $\beta 1-6)$ arranged in a Greek key motif, while the $C$-terminal domain consists of four $\beta$ strands ( $\beta 7-10)$. Three disulfide bonds (6 cysteine residues) give rigidity within the $\mathrm{N}$-terminal domain and one disulfide bond ( 2 cysteine residues) gives rigidity within the C-terminal domain. A fifth, single disulfide bond between $\mathrm{C} 37$ and $\mathrm{C} 73$ links the $\mathrm{N}$-terminal and $\mathrm{C}$ terminal domains. In marsupial USM, the cysteine residue homologous to C37 (= C40 in tammar secreted USM1) is conserved, despite the absence of C73. However, an additional cysteine residue $(=\mathrm{C} 59$ in the

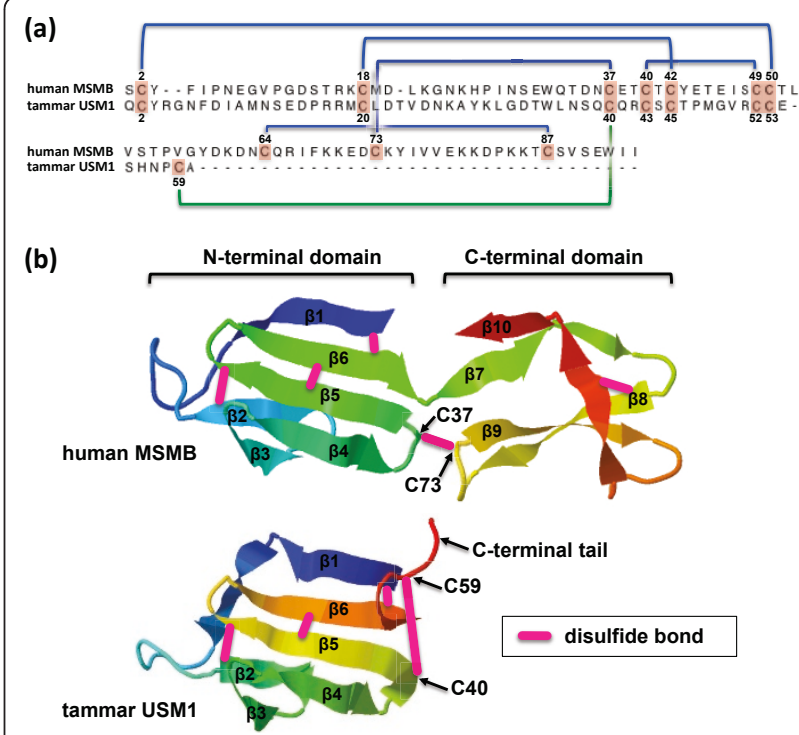

Figure 8 Predicted tertiary structure of tammar USM1 modelled on human MSMB. (a) The secreted forms of human MSMB and tammar USM1 (predicted) are aligned with the Nterminal domain (above) and the C-terminal domain (below). The ten cysteine residues in MSMB (highlighted in pink with positions indicated) form five disulfide bonds as shown (blue lines). Cysteine residues homologous to $\mathrm{C} 64, \mathrm{C} 73$ and $\mathrm{C} 87$ are absent in USM1 due to its C-terminal truncation, leaving C40 in USM1 (homologous to C37 in MSMB) unpaired. We suggest that an additional C-terminal cysteine residue (C59), also conserved in brushtail possum and opossum, instead forms a disulfide bond with C40. (b) The secreted forms of human MSMB (monomer) and tammar USM1 modelled on the crystal structure of human MSMB [35] (Protein Data Bank accession code 3 IX0) using ESyPred3D $[65,66]$ and displayed as a cartoon with $\beta$ strands in rainbow colour using Jmol [67]. The approximate positions of disulfide bonds are indicated by pink bars. Predicted disulfide bonds in tammar USM are shown in homologous positions. It is evident that C40 and C59, which lies within the short, flexible C-terminal tail, are in close proximity and likely to form a disulfide bond. 
tammar secreted protein) is present within the short, six-residue C-terminal domain of all marsupial USM orthologues. Modelling of the tammar USM1 tertiary structure showed that this cysteine residue would lie very close to C37 and substitute for the missing C73 (Figure 8b).

The crystal structure of MSMB also revealed a mechanism for dimerisation, whereby the $\beta 1$ and $\beta 10$ strands of one molecule lie end-to-end to form a straight edge which lies antiparallel and in contact with the $\beta 1$ and $\beta 10$ strands of a second molecule [35]. The involvement of both $\beta 1$ (N-terminal domain) and $\beta 10$ (C-terminal domain) strands suggests that dimerisation cannot occur in USM, which lacks sequence homologous to $\beta 10$. This might be integral to a divergent role for USM compared with MSMB and USMH. However, the molecular masses of bands 3-5 in the original protein gel of [2] (Figure 1), which each contained USM sequence, were estimated by the authors as 22, 17 and $14 \mathrm{kDa}$, respectively. Bands 3 and 5 are thus approximately three- and two-fold, respectively, the predicted molecular mass of monomeric secreted USM (7 kDa). It thus remains possible that USM can form multimers despite its C-terminal truncation. It is noteworthy that the immunoglobulin-binding property of MSMB may depend on dissociation of dimers to monomers in response to reducing conditions or low $\mathrm{pH}[35,36]$

The precise role of USM in the marsupial postovulatory coats is an intriguing question considering the various roles that have been proposed for MSMB. While MSMB was first identified almost three decades ago as a component of human seminal plasma with FSH-inhibiting activity [16], there has been a recent resurgence in interest due to a demonstrated genetic link with prostate cancer susceptibility [37-40]. Perhaps more relevant to the present context, MSMB has been shown to inhibit sperm binding and the acrosome reaction [11,41], suggestive of a possible role in blocking polyspermy in marsupials.

\section{Expression of USM, MSMB and MSMP in tammar tissues}

To elucidate distinctions in the roles of USM, MSMB and MSMP in the tammar, RT-PCR was performed on a variety of tissues (Figure 9). USM1 expression was detected solely within endometrium and not in other tissues, including oviduct. This is consistent with a highly specific role for USM1 as a component of the postovulatory coats. $M S M B$ expression was detected in both pituitary gland and testis, while $M S M P$ expression was restricted to testis only. Expression of USM2 was not detected in the tissues tested.

Expression of USM1 was examined by quantitative RT-PCR during gestation (Figure 10). Transcript levels were moderate-to-high during pre-diapause (days 0-7

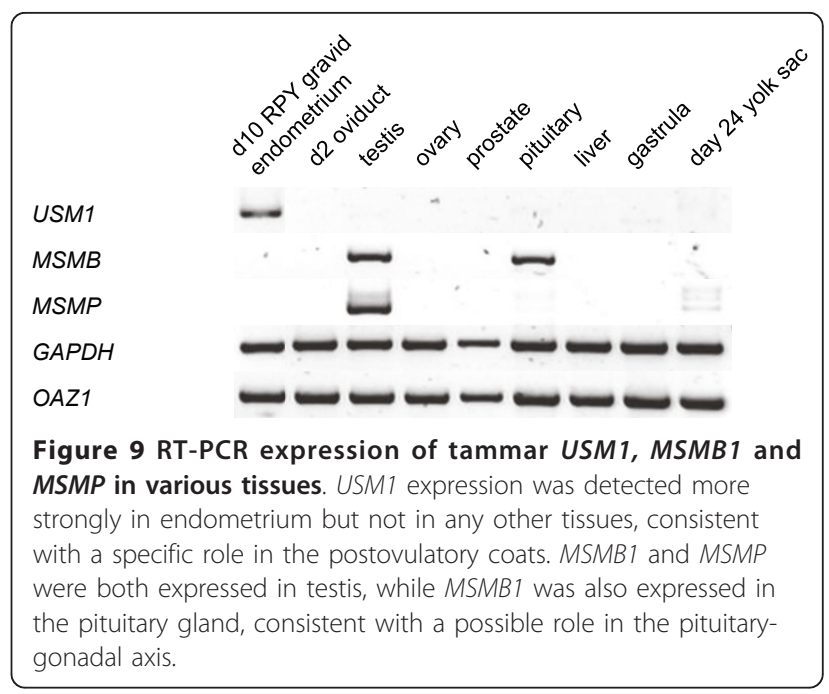

after birth of previous young), diapause, and early postdiapause (until day 17-18 after blastocyst reactivation by removal of pouch young (RPY)). Levels were higher during diapause than pre-diapause and the earliest post-diapause stages, although these differences were not significant. By contrast, the second peak at around d1015 RPY was significantly higher than d4-d6 RPY and d20-25 RPY. After d15 RPY there was a rapid reduction in USM1 transcript levels, which coincides with shell breakdown at around d18-19 RPY [7].

The dynamic temporal expression pattern of USM1 during gestation suggests that it may be at least partly regulated by progesterone - indeed we identified a progesterone receptor binding site within the first intron

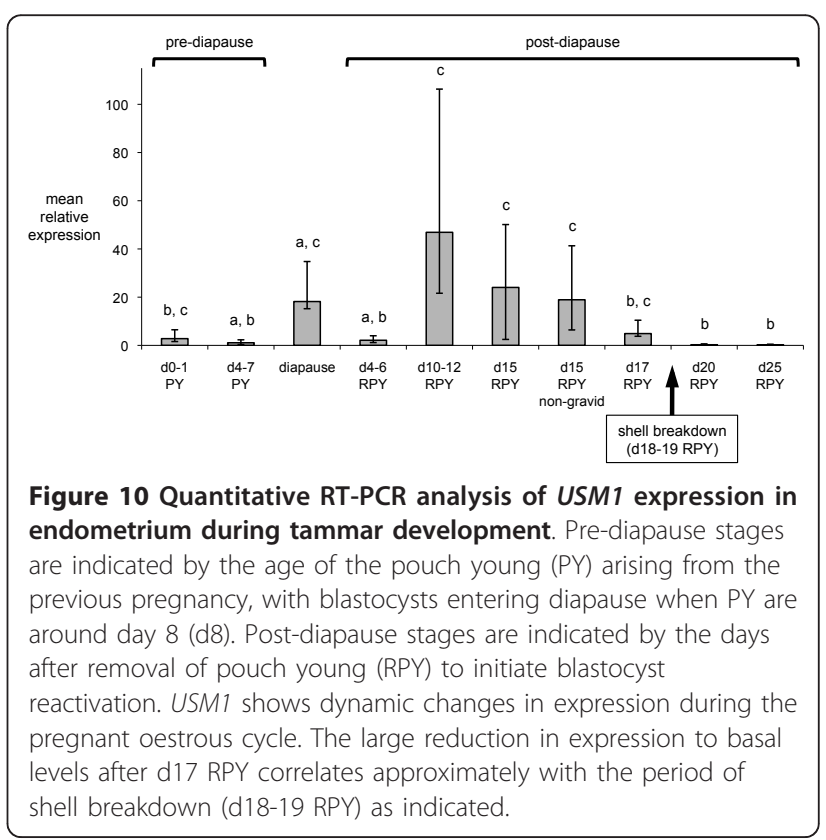


that was conserved in both tammar and opossum (not shown). In the tammar, progesterone receptors are highest at around d5 RPY, together with oestrogen receptors, coinciding with the progesterone and oestrogen pulses that occur at this time [42]. Interestingly this is exactly when USM1 is at its lowest level before increasing again. USM1 expression is also low after $\mathrm{d} 20$ of pregnancy (Figure 10), at the time when progesterone concentrations in the corpus luteum [43], in the peripheral circulation [44], and in the utero-ovarian circulation [45] are highest, but progesterone receptor levels are very low [42]. Thus, USM1 expression appears to follow the profile of progesterone receptor levels rather than of progesterone.

\section{USM as a component of the marsupial postovulatory coats}

The mucoid layer is deposited during passage through the oviduct whereas shell coat material is secreted from endometrial glands within the uterus and the uterotubal junction. The association of MSMB expression with mucosal epithelia [46] suggests that USM might contribute to the mucin layer, however, the brushtail possum protein bands isolated by Casey et al. [2] were derived from a mixed pool of coats from early cleavage through to late expansion conceptuses. Coats of the former would be expected to include more mucoid coat while the latter would include more shell coat. The much greater volume of shell coat surrounding late-expansion conceptuses [5] suggests that shell coat material would predominate in any mixed pool of samples. Indeed, expression in the endometrium but not the oviduct revealed by our RT-PCR data is consistent with contribution to the shell coat rather than the mucin layer, which forms first in the oviduct. Nevertheless, there may be some overlap in the components of both layers, with the physical differences between the shell and mucin coat due to a subset of components that are specific to one or the other. Immunolocalisation studies may clarify the relative contribution of USM to each layer.

Many of the known properties of MSMB provide clues as to possible role(s) of USM. In marsupials, intimate contact between conceptus and maternal tissues occurs only late in development, after shell breakdown approximately two-thirds of the way through pregnancy $[47,48]$. The binding of MSMB to immunoglobulins [12] suggests that USM, if it shares this property, may interact with the maternal immune system to modulate its action. The apparently synchronised down-regulation of tammar USM1 with shell breakdown suggests that the former may be a necessary step for subsequent successful implantation. Alternatively, USM1 down-regulation might facilitate shell-breakdown itself.
USM could also have an immune role in protection against pathogens within the uterus. We have identified a lysozyme as another component of the postovulatory coats (unpublished data) that may have a similar role in protection against bacteria. Such a role for USM would be consistent with the association of MSMB secretion in mucosal tissues [49]. In eutherians, degradation of mucin on the endometrial surface is associated with a window of receptivity to implantation (reviewed [50]). Thus it is possible that similar events, including downregulation of USM expression, are associated with placental attachment after shell breakdown in marsupials.

Unlike MSMP, which is relatively well conserved, MSMB is characterised by a rapid rate of evolution. Mäkinen et al. [27] noted that among the multiple copies of $M S M B$ in New World monkeys, the second intron is more highly conserved than the exons and there is no bias towards substitutions in the third nucleotide of codons, which normally preserve amino acid identity. Thus it is possible that rapid change in the primary structure of MSMB, excluding the signal peptide and the cysteine residues, is under positive selection. In another study [51], MSMB was identified in a screen for prostate-expressed genes in primates with a high ratio of nonsynonymous to synonymous substitution rate $\left(d_{\mathrm{N}} / d_{\mathrm{S}}\right)$ - a conservative measure of positive selection. USM is similarly highly divergent among the three marsupial species examined and, like MSMB, its divergence might be due to positive rather than neutral selection. It was previously proposed that MSMB prevents immune attack against allogeneic sperm [12]. A possible extension to this idea may be that the same mechanism also serves to reject heterospecific sperm, as MSMB has been shown to bind sperm and act as an inhibitor of sperm motility and the acrosome reaction $[10,11,41]$. Thus rapid evolution of USM (and MSMB) could be implicated in speciation events by preventing hybridisation with closely related species. A recent report [24] showed that male longfin inshore squid (Loligo pealeii) detect an MSMB-like protein, Loligo $\beta$ MSP, in the capsule of eggs laid on the sea floor. Loligo $\beta$-MSP triggers hostile behaviour in conspecific males towards other male squid, demonstrating a possible role in species recognition. It is not clear whether this reflects only a secondary role for Loligo $\beta$-MSP in the egg capsule, but the parallel with USM as a component of the marsupial conceptus coats is intriguing, although in marsupials internal fertilisation and development rules out any role for USM in mate selection by males. However, it remains possible that USM within the reproductive tract helps to ensure fertilisation by only con-specific sperm.

Some eutherians such as rabbit, horse and some carnivores (reviewed [52-54]) also possess various post- 
ovulatory conceptus coats, such as a mucoid coat, neozona and gloiolemma (rabbit) or a capsule (horse). It is not known whether any components of marsupial and eutherian mucoid coats are homologous, but our thorough searches in both rabbit and horse genome databases suggest that no orthologues of USM are present. However, other components could be homologous. It also cannot be excluded that MSMB or MSMP have acquired an analogous role in the coats of some eutherians by convergent evolution. It is noteworthy that $M S M B$ expression has also been detected in human endometrium [55].

Very few genes have been identified in marsupials that are absent in eutherian genomes [9]. The identification of USM is thus noteworthy and could be highly relevant to understanding the differences in modes of reproduction between these two major mammalian groups. If USM homologues in non-mammalian vertebrates have a different role to marsupial USM, this would suggest that the latter evolved in concert with mammalian viviparity by supporting in utero development. Conversely, the absence of USM in eutherians suggests the evolution of alternate mechanisms supporting in utero development that caused USM to be redundant, for presumably the same reason that the shell coat became redundant.

\section{Conclusions}

Very few genes have been identified that are specific to marsupials, one of the three major extant groups of mammals. We have identified one such gene - USM and attributed to its product a role in the postovulatory coats of the marsupial conceptus. Its likely importance in reproduction has potential applications in fertility control and its high sequence divergence may facilitate species-specificity when targeting wild populations. We have also provided the most comprehensive analysis to date of the complex evolutionary relationships between different members of the vertebrate USM-MSMB$M S M P$ gene family. Despite more than 30 years since the initial identification of MSMB, this gene family remains poorly understood. It has attracted attention in multiple, diverse fields of research, including immunity, reproduction, sexual selection and cancer. Our results provide valuable information that may help to elucidate not only the evolution of viviparity and placental function in mammals, but also the roles of MSMB and MSMP.

\section{Methods}

\section{Animals and tissue sampling}

Tammar samples were collected from animals shot on Kangaroo Island, South Australia, or from captive animals from a colony maintained by the University of Melbourne. Tissues from adult tammars were frozen in liquid nitrogen. All tissues were collected under appropriate permits. Experiments were approved by the University of Melbourne Animal Experimentation Ethics Committee and all animal handling and husbandry was in accordance with the National Health and Medical Research Council of Australia (2004) guidelines.

\section{RNA extraction and reverse transcription}

Total RNA was extracted using Tri Reagent (Ambion) and DNase-treated using DNA-free (Ambion). Reverse transcription was performed using the Transcriptor High Fidelity cDNA Synthesis Kit (Roche) with oligo-dT priming.

\section{RT-PCR}

The complete coding region of tammar USM1 cDNA was amplified using the primers 5'-GGGGCACGAATGGGTGTTTATTC-3' and 5'-CCTGAGACACAGAGGAACCAGAGGTACTG-3' and TaKaRa ExTaq polymerase according to the manufacturer's protocol. The PCR product was cloned using the pGEM-T-Easy kit (Promega) and sequenced using vector-specific primers. The transcription start site was identified by nested 5' RACE using the SMARTer RACE cDNA Amplication Kit (ClonTech) and the reverse primers 5'CCTGAGACACAGAGGAACCAGAGGTACTG-3' (first PCR) and 5'-CAGACCAATCAGACGCTCC-3' (nested PCR). The purified 5' RACE product was directly sequenced using the nested reverse primer.

Semi-quantitative RT-PCR on cDNA from adult tissues was performed using the following primers. USM1 - 5'-GGGGCACGAATGGGTGTTTATTC and CCTGAGACACAGAGGAACCAGAGGTACTG; USM2 - 5'TGTTGGCAAGAAGGGTCAATGTCC-3' and TTCC TGAGAGGTACAGGTGTCAGTTATGC-3'; MSMB1 5'-GATTGCTGCTGGTCTCGTGACTACTG-3' and AGGATTTGGTGGGGTCTTCTTTATGC; MSMP - 5'GGTAGTGGTCAATGGAG TTGCTGATGC-3' and 5'-ACTTCGGAGCCAGGATTCACCC-3'; GAPDH - 5'CCTACTCCCAATGTATCTGTTGTGG-3' and 5'GGTGGAACTCCTTTTT TGACTGG-3'. Amplification was performed using the following programme: $95^{\circ} \mathrm{C}$ for 1 minute; 35 cycles of $95^{\circ} \mathrm{C}$ for 15 seconds, $60^{\circ} \mathrm{C}$ for 15 seconds, $72^{\circ} \mathrm{C}$ for 30 seconds; $72^{\circ} \mathrm{C}$ for two minutes.

\section{Quantitative RT-PCR}

Quantitative RT-PCR (qRT-PCR) was performed using the Brilliant II SYBR Green qPCR Kit (Agilent Technologies) and reactions run in triplicate on an Mx3000P thermal cycler (Stratagene). The quantities of tammar USM1 transcripts, using the primers 5'-GGGGCACGAATGGGTGTTTATTC-3' and 5'-CCTGAGACACAGAGGAACCAGAGGTACTG-3', were compared to the housekeeping gene $\beta$-ACTIN, using the primers $5^{\prime}$ - 
TTGCTGACAGGATGCAGAAG-3' and 5'-AAAGCCATG-CCAATCTCATC-3'. Amplification was performed using the following program: $95^{\circ} \mathrm{C}$ for 15 minutes; 50 cycles of $95^{\circ} \mathrm{C}$ for 15 seconds, $60^{\circ} \mathrm{C}$ for 30 seconds (which included the plate read) and $72^{\circ} \mathrm{C}$ for 30 seconds. This was followed by $95^{\circ} \mathrm{C}$ for 1 minute and a dissociation curve of $55^{\circ} \mathrm{C}$ to $95^{\circ} \mathrm{C}$, with a reading every $0.5^{\circ} \mathrm{C}$ over 30 seconds.

Plates were discarded if more than one of the negative control triplicates was contaminated. Individual samples of a triplicate were also discarded if they had irregular melting curves or if the coefficient of variation was greater than 0.05 for the triplicate. If more than one of the triplicates was irregular the sample was repeated or discarded. In addition, a calibrator sample (d4-5 PY stage gravid endometrium) was also run across all plates to control for inter-assay variation, and the efficiency of each primer set was also determined. Analysis of the data was based on a modification of the 'efficiency-corrected comparative quantification method', which incorporates both the individual efficiencies of each primer set and the calibrator sample into the calculations [56]. This gave a normalised relative quantity value for each sample, which was then used for the subsequent analysis.

Statistical analyses were conducted using $\mathrm{R}$ (version 2.11.1) [57]. A Shapiro-Wilks test for normality was performed to check the assumption that the data had a normal distribution. Since the distribution of the relative expression values was skewed, the data were log transformed for analysis. Log transformed data was analysed by one-way ANOVA with multiple comparisons of means compared using Tukey contrasts. For all analyses a significance level of $\mathrm{p}<0.05$ was used. Data are presented as mean \pm SEM after converting back to nontransformed normalised relative expression.

\section{Bioinformatics}

Sequence searches of Whole Genome Shotgun, Expressed Sequence Tag and Nucleotide databases were performed through the National Center for Biotechnology Information (NCBI) website [58] using BLAST and tBLASTn and modifying search parameters for stringency. Nucleotide and translated sequences were analysed using the MacVector sequence analysis software package. Protein molecular masses were predicted using MacVector's Protein Analysis Toolbox. Signal peptide cleavage sites were identified using the SignalP 3.0 webbased software [59] with default parameters.

\section{BAC identification and sequencing}

A tammar BAC genomic library (MEB1) was screened by PCR using primers 5'- GGGGCACGAATGGGTGTTTATTC -3' and 5'- GGAAGAGTGGAGGATGGATTTGAGG -3'. Illumina 454 sequencing was performed by the Australian Genome Research Facility. The longest assembled contig $(89,803$ nucleotides) was submitted to GenBank [accession JN251945].

\section{Phylogenetic analysis}

Translated sequences were aligned using ClustalW [60] within the MacVector sequence analysis software package. The unrooted phylogenetic tree was produced using Phylip (version 3.69) software [61] and running sequentially the programs protdist, neighbor and drawtree with default parameters. The tree was displayed and edited using Adobe Illustrator.

\section{Promoter analysis}

Promoter analysis was performed by aligning tammar USM1 and opossum USM genomic sequences using Mulan online software http://mulan.dcode.org/[62,63] in 'TBA' mode. Conserved candidate transcription factor binding sites were identified using multiTF $[63,64]$ from the Mulan website, selecting the TRANSFAC professional V10.2 TFBS database for vertebrates, and selecting the "optimised for function" option for matrix similarity.

\section{Additional material}

Additional file 1: Alignment of translated sequences of selected members of the USM/MSMB/MSMP family. Protein sequences are grouped according to sub-family. Boundaries between regions encoded by Exons 2, 3 and 4 are indicated by orange lines. Shading indicates identity in at least $50 \%$ of sequences. The predicted signal peptide cleavage site for USM orthologues is indicated by an arrowhead.

Additional file 2: Sources of sequences used in this study. Transcript sequence sources are provided either as GenBank or UniGene accession numbers. Coding regions predicted from this study are defined by nucleotide ranges within genomic sequences, either from genome builds or whole genome shotgun scaffolds or contigs, as specified. Exons 1-4 refer for MSMP are defined for ease of comparison by their homology with Exons 1-4 of human MSMB.

Additional file 3: Phylogenetic tree of microproteins from chordates using an alignment of protein sequences. The unrooted tree was

constructed by aligning translated sequences homologous to Exons 3-4 of mouse Msmb and subjecting the alignment to the program Protpars (Phylip) followed by Drawtree. Most branch points do not yield significant bootstrap values using various methods (not shown), but sequences generally cluster into the three groups highlighted. Accordingly, the position of zebrafish usmh1 in the tree is unlikely to reflect its true phylogeny, as predicted by its conserved synteny.

Additional file 4: Amino acid identity and similarity matrices for avian MSMB1, MSMB2 and MSMB3 and mouse Msmb. Highlighted cells refer to values cited in the text. Yellow: percentage identities between each zebra finch paralogue and its orthologues in other species are highest for MSMB3. Blue: percentage identities between the turkey and chicken orthologues of each paralogue are also highest for MSMB3. Orange: mouse Msmb shows higher identity to MSMB2 than to either MSMB1 or MSMB3.

\section{Acknowledgements}

We thank Scott Brownlees for assistance with animal handling and Brandon Menzies and Andrew Pask for helpful suggestions. 


\section{Authors' contributions}

SF performed bioinformatical analyses, semiquantitative RT-PCR and cloning. JF performed quantitative RT-PCR. BD performed BAC library screening. SF, $J F, G S$ and MBR analysed data and prepared the manuscript. All authors read and approved the final manuscript.

Received: 2 August 2011 Accepted: 30 December 2011 Published: 30 December 2011

\section{References}

1. Selwood L: Marsupial egg and embryo coats. Cells Tissues Organs 2000, 166(2):208-219.

2. Casey NP, Martinus R, Selwood L: Outer egg coats of the marsupial conceptus: secretion and protein composition. Mol Reprod Dev 2002, 62(2):181-194.

3. Roberts $C T$, Breed WG, Mayrhofer G: Origin of the oocyte shell membrane of a dasyurid marsupial: an immunohistochemical study. J Exp Zool 1994, 270(3):321-331.

4. Renfree MB, Lewis AM: Cleavage in vivo and in vitro in the Marsupial Macropus eugenii. Reprod Fertil Dev 1996, 8(4):725-742.

5. Shaw $\mathrm{G}$ : The uterine environment in early pregnancy in the tammar wallaby. Reprod Fertil Dev 1996, 8(4):811-818.

6. Hughes RL: Morphological studies on implantation in marsupials. J Reprod Fertil 1974, 39(1):173-186.

7. Denker HW, Tyndale-Biscoe CH: Embryo implantation and proteinase activities in a marsupial (Macropus eugenii). Histochemical patterns of proteinases in various gestational stages. Cell Tissue Res 1986, 246(2):279-291.

8. Cui S, Selwood L: Cloning and expression of a novel CDNA encoding shell coat protein, $\mathrm{cp} 4$, from the brushtail possum (Trichosurus vulpecula). Mol Reprod Dev 2003, 65(2):141-147.

9. Mikkelsen TS, Wakefield MJ, Aken B, Amemiya CT, Chang IL, Duke S, Garber M, Gentles AJ, Goodstadt L, Heger A, et al: Genome of the marsupial Monodelphis domestica reveals innovation in non-coding sequences. Nature 2007, 447(7141):167-177.

10. Jeng H, Liu KM, Chang WC: Purification and characterization of reversible sperm motility inhibitors from porcine seminal plasma. Biochem Biophys Res Commun 1993, 191(2):435-440.

11. Chao CF, Chiou ST, Jeng H, Chang WC: The porcine sperm motility inhibitor is identical to beta-microseminoprotein and is a competitive inhibitor of $\mathrm{Na}+\mathrm{K}(+)$-ATPase. Biochem Biophys Res Commun 1996, 218(2):623-628.

12. Maeda N, Kamada M, Daitoh T, Aono T, Futaki S, Liang ZG, Koide SS: Immunoglobulin binding factor in human seminal plasma: immunological function. Arch Androl 1993, 31(1):31-36.

13. Aoki N, Sakiyama A, Kuroki K, Maenaka K, Kohda D, Deshimaru M, Terada S: Serotriflin, a CRISP family protein with binding affinity for small serum protein-2 in snake serum. Biochim Biophys Acta 2008, 1784(4):621-628.

14. Aoki N, Sakiyama A, Deshimaru M, Terada S: Identification of novel serum proteins in a Japanese viper: homologs of mammalian PSP94. Biochem Biophys Res Commun 2007, 359(2):330-334.

15. Lazure C, Villemure M, Gauthier D, Naude RJ, Mbikay M: Characterization of ostrich (Struthio camelus) beta-microseminoprotein (MSP): identification of homologous sequences in EST databases and analysis of their evolution during speciation. Protein Sci 2001, 10(11):2207-2218.

16. Sheth AR, Arabatti N, Carlquist M, Jornvall H: Characterization of a polypeptide from human seminal plasma with inhibin (inhibition of FSH secretion)-like activity. FEBS Lett 1984, 165(1):11-15.

17. Thakur AN, Vaze AY, Dattatreyamurthy B, Sheth AR: Isolation \& characterization of inhibin from human seminal plasma. Indian J Exp Biol 1981, 19(4):307-313.

18. Garde SV, Basrur VS, Li L, Finkelman MA, Krishan A, Wellham L, Ben-Josef E, Haddad M, Taylor JD, Porter AT, et al: Prostate secretory protein (PSP94) suppresses the growth of androgen-independent prostate cancer cell line (PC3) and xenografts by inducing apoptosis. Prostate 1999, 38(2):118-125.

19. Lokeshwar BL, Hurkadli KS, Sheth AR, Block NL: Human prostatic inhibin suppresses tumor growth and inhibits clonogenic cell survival of a model prostatic adenocarcinoma, the Dunning R3327G rat tumor. Cancer Res 1993, 53(20):4855-4859.
20. Mundle SD, Sheth NA: Suppression of DNA synthesis and induction of apoptosis in rat prostate by human seminal plasma inhibin (HSPI). Cell Biol Int 1993, 17(6):587-594.

21. Sheth NA, Teni TR, Mundle SD: Dual regulatory action of prostatic inhibin (10.7 kDa) on DNA synthesis. Indian J Exp Biol 1992, 30(11):1024-1029.

22. Shukeir N, Arakelian A, Kadhim S, Garde S, Rabbani SA: Prostate secretory protein PSP-94 decreases tumor growth and hypercalcemia of malignancy in a syngenic in vivo model of prostate cancer. Cancer Res 2003, 63(9):2072-2078.

23. Valtonen-Andre C, Bjartell A, Hellsten R, Lilja $H$, Harkonen P, Lundwall A: A highly conserved protein secreted by the prostate cancer cell line PC-3 is expressed in benign and malignant prostate tissue. Biol Chem 2007, 388(3):289-295.

24. Cummins SF, Boal JG, Buresch KC, Kuanpradit C, Sobhon P, Holm JB, Degnan BM, Nagle GT, Hanlon RT: Extreme aggression in male squid induced by a beta-MSP-like pheromone. Curr Biol 2011, 21(4):322-327.

25. Jaillon O, Aury JM, Brunet F, Petit JL, Stange-Thomann N, Mauceli E, Bouneau L, Fischer C, Ozouf-Costaz C, Bernot A, et al: Genome duplication in the teleost fish Tetraodon nigroviridis reveals the early vertebrate proto-karyotype. Nature 2004, 431(7011):946-957.

26. Aoki N, Matsuo H, Deshimaru M, Terada S: Accelerated evolution of small serum proteins (SSPs)-The PSP94 family proteins in a Japanese viper. Gene 2008, 426(1-2):7-14

27. Makinen M, Valtonen-Andre C, Lundwall A: New world, but not Old World, monkeys carry several genes encoding beta-microseminoprotein. Eur J Biochem 1999, 264(2):407-414.

28. Warr GW: A $12 \mathrm{kDa}$ protein in chicken serum antigenically cross-reactive with, but unrelated to, beta 2-microglobulin. Dev Comp Immunol 1990, 14(2):247-253.

29. Huang HL, Cheng YS, Huang CW, Huang MC, Hsu WH: A novel genetic marker of the ovomucoid gene associated with hatchability in Tsaiya ducks (Anas platyrhynchos). Animal Genetics 2011, no-no.

30. Hackett SJ, Kimball RT, Reddy S, Bowie RC, Braun EL, Braun MJ, Chojnowski JL, Cox WA, Han KL, Harshman J, et al: A phylogenomic study of birds reveals their evolutionary history. Science 2008, 320(5884):1763-1768.

31. Gordon WL, Liu WK, Akiyama K, Tsuda R, Hara M, Schmid K, Ward DN: Betamicroseminoprotein (beta-MSP) is not an inhibin. Biol Reprod 1987, 36(4):829-835

32. Kohan S, Froysa B, Cederlund E, Fairwell T, Lerner R, Johansson J, Khan S, Ritzen M, Jornvall H, Cekan S, et al: Peptides of postulated inhibin activity. Lack of in vitro inhibin activity of a 94-residue peptide isolated from human seminal plasma, and of a synthetic replicate of its C-terminal 28residue segment. FEBS Lett 1986, 199(2):242-248.

33. Ghasriani $H$, Teilum $K$, Johnsson Y, Fernlund P, Drakenberg T: Solution structures of human and porcine beta-microseminoprotein. J Mol Biol 2006, 362(3):502-515.

34. Wang I, Yu TA, Wu SH, Chang WC, Chen C: Disulfide pairings and secondary structure of porcine beta-microseminoprotein. FEBS Lett 2003, 541(1-3):80-84

35. Kumar A, Jagtap DD, Mahale SD, Kumar M: Crystal structure of prostate secretory protein PSP94 shows an edge-to-edge association of two monomers to form a homodimer. J Mol Biol 2010, 397(4):947-956.

36. Mori H, Kamada M, Maegawa M, Yamamoto S, Aono T, Futaki S, Yano M, Kido H, Koide SS: Enzymatic activation of immunoglobulin binding factor in female reproductive tract. Biochem Biophys Res Commun 1998, 246(2):409-413.

37. Chang BL, Cramer SD, Wiklund F, Isaacs SD, Stevens VL, Sun J, Smith S, Pruett $\mathrm{K}$, Romero LM, Wiley KE, et al: Fine mapping association study and functional analysis implicate a SNP in MSMB at $10 \mathrm{q} 11$ as a causal variant for prostate cancer risk. Hum Mol Genet 2009, 18(7):1368-1375.

38. Eeles RA, Kote-Jarai Z, Giles GG, Olama AA, Guy M, Jugurnauth SK, Mulholland S, Leongamornlert DA, Edwards SM, Morrison J, et al: Multiple newly identified loci associated with prostate cancer susceptibility. Nat Genet 2008, 40(3):316-321.

39. Lou H, Yeager M, Li H, Bosquet JG, Hayes RB, Orr N, Yu K, Hutchinson A, Jacobs $K B$, Kraft $P$, et al: Fine mapping and functional analysis of a common variant in MSMB on chromosome 10q11.2 associated with prostate cancer susceptibility. Proc Natl Acad Sci USA 2009, 106(19):7933-7938. 
40. Thomas G, Jacobs KB, Yeager M, Kraft P, Wacholder S, Orr N, Yu K, Chatterjee N, Welch R, Hutchinson A, et al: Multiple loci identified in a genome-wide association study of prostate cancer. Nat Genet 2008 , 40(3):310-315

41. Anahi Franchi N, Avendano C, Molina RI, Tissera AD, Maldonado CA Oehninger S, Coronel CE: beta-Microseminoprotein in human spermatozoa and its potential role in male fertility. Reproduction 2008 136(2):157-166.

42. Renfree $M B$, Blanden $D R$ : Progesterone and oestrogen receptors in the female genital tract throughout pregnancy in tammar wallabies. J Reprod Fertil 2000, 119(1):121-128

43. Renfree MB, Green SW, Young IR: Growth of the corpus luteum and its progesterone content during pregnancy in the tammar wallaby, Macropus eugenii. J Reprod Fertil 1979, 57(1):131-136.

44. Hinds LA, Tyndale-Biscoe CH: Plasma progesterone levels in the pregnant and non-pregnant tammar, Macropus eugenii. J Endocrinol 1982, 93(1):99-107.

45. Towers PA, Shaw G, Renfree MB: Urogenital vasculature and local steroid concentrations in the uterine branch of the ovarian vein of the female tammar wallaby (Macropus eugenii). J Reprod Fertil 1986, 78(1):37-47.

46. Ulvsback M, Spurr NK, Lundwall A: Assignment of the human gene for beta-microseminoprotein (MSMB) to chromosome 10 and demonstration of related genes in other vertebrates. Genomics 1991, 11(4):920-924

47. Freyer C, Zeller U, Renfree MB: Placental function in two distantly related marsupials. Placenta 2007, 28(2-3):249-257.

48. Freyer $C$, Zeller $U$, Renfree MB: The marsupial placenta: a phylogenetic analysis. J Exp Zool A Comp Exp Biol 2003, 299(1):59-77.

49. Weiber $H$, Andersson C, Murne A, Rannevik G, Lindstrom C, Lilja $H$ Fernlund P: Beta microseminoprotein is not a prostate-specific protein. Its identification in mucous glands and secretions. Am J Pathol 1990, 137(3):593-603.

50. Thathiah A, Carson DD: Mucins and blastocyst attachment. Rev Endocr Metab Disord 2002, 3(2):87-96.

51. Clark NL, Swanson WJ: Pervasive adaptive evolution in primate seminal proteins. PLoS Genet 2005, 1(3):e35.

52. Denker HW: Structural dynamics and function of early embryonic coats. Cells Tissues Organs 2000, 166(2):180-207.

53. Betteridge $\mathrm{KJ}$ : The structure and function of the equine capsule in relation to embryo manipulation and transfer. Equine Veterinary Journal 1989, 21(S8):92-100.

54. Renfree MB: Implantation and placentation. In Reproduction in Mammals. Volume 2. Edited by: Austin CR, Short RV. Cambridge: Cambridge University Press; 1982:26-69.

55. Baijal-Gupta M, Clarke MW, Finkelman MA, McLachlin CM, Han VK: Prostatic secretory protein (PSP94) expression in human female reproductive tissues, breast and in endometrial cancer cell lines. J Endocrinol 2000, 165(2):425-433.

56. Hellemans J, Mortier G, Paepe AD, Speleman F, Vandesompele J: qBase relative quantification framework and software for management and automated analysis of real-time quantitative PCR data. Genome Biology 2007, 8(2):1-14.

57. R Development Core Team: R: A language and environment for statistical computing. R Foundation for Statistical Computing; 2010, 2.11.1 edn:

58. National Center for Biotechnology Information. [http://www.ncbi.nlm.nih. gov/].

59. SignalP 3.0 Server. [http://www.cbs.dtu.dk/services/SignalP/].

60. Larkin MA, Blackshields G, Brown NP, Chenna R, McGettigan PA, McWilliam H, Valentin F, Wallace IM, Wilm A, Lopez R, et al: Clustal W and Clustal $\times$ version 2.0. Bioinformatics 2007, 23(21):2947-2948.

61. PHYLIP (Phylogeny Inference Package) version 3.6. [http://www.phylip $\mathrm{com} /]$.

62. Ovcharenko I, Loots GG, Giardine BM, Hou M, Ma J, Hardison RC, Stubbs L, Miller W: Mulan: multiple-sequence local alignment and visualization for studying function and evolution. Genome Res 2005, 15(1):184-194.

63. Loots GG, Ovcharenko I: Mulan: multiple-sequence alignment to predict functional elements in genomic sequences. Methods Mol Biol 2007, 395:237-254.

64. Loots GG, Ovcharenko I: Dcode.org anthology of comparative genomic tools. Nucleic Acids Res 2005, 33 Web Server issue: W56-64
65. Lambert C, Leonard N, De Bolle X, Depiereux E: ESyPred3D: Prediction of proteins 3D structures. Bioinformatics 2002, 18(9):1250-1256.

66. Jones CM, Broadbent J, Thomas PQ, Smith JC, Beddington RS: An anterior signalling centre in Xenopus revealed by the homeobox gene XHex. Curr Biol 1999, 9(17):946-954.

67. Jmol: an open-source Java viewer for chemical structures in 3D. [http:// www.jmol.org/].

doi:10.1186/1471-2148-11-373

Cite this article as: Frankenberg et al:: A novel MSMB-related microprotein in the postovulatory egg coats of marsupials. BMC Evolutionary Biology 2011 11:373.

\section{Submit your next manuscript to BioMed Central and take full advantage of:}

- Convenient online submission

- Thorough peer review

- No space constraints or color figure charges

- Immediate publication on acceptance

- Inclusion in PubMed, CAS, Scopus and Google Scholar

- Research which is freely available for redistribution

Submit your manuscript a www.biomedcentral.com/submit
C Biomed Central 